\title{
Концепция жизненных циклов: необходимо ли ее понимание и применение финансистами на российском рынке?
}

\author{
Глухова Е.B. ${ }^{42}$
}

Известные теории жизненного ичикла организации [Adizes I., 1988 ] [Грейнер Л., 2002] описывают управленческие практики, характерные для того или иного этапа развития компании. Появился ряд исследований, доказавших, что финансовые характеристики компании изменяются при переходе от одного этапа жизненного ичикла к другому. Практически все исследования, подтверждающие возможность применения этих теорий на практике, проводились на развитых западных (в основном американских) рынках, и по понятным причинам в них рассматривались публичные компании. $B$ статье рассматривается вопрос о возможности применения этих теорий для российского бизнеса, включая средний и компании закрытого типа. Автор $c$ позиций собственного профессионального опьта финансиста показывает, что понимание конщепции ЖЦО необходимо не только маркетологам и управленцам, но и финансовым аналитикам для понимания объективных законов развития компании, что дает возможность не только более четко анализировать текущее состояние организации, но и строить прогнозы на будущее.

Одной из плодотворных управленческих теоретических концепций XX в. является теория жизненного цикла организации (ЖЦО). Эта идея похожа на концепцию жизненного цикла товара, которая утверждает, что такой цикл состоит из стадий внедрения, роста, зрелости и спада. Все эти стадии различаются динамикой продаж и уровнями прибыльности. И маркетологи сейчас практически уже не спорят о том, что эта концепция имеет право на существование, а пытаются понять, что влияет на этот объективный процесс и как им можно управлять.

А как следует относиться в практике менеджмента к концепции жизненного цикла организации? Как определить их жизненный цикл? И для каких конкретных, практических задач важно понимание концепции жизненного цикла? И кому в организации важно понимать, на каком этапе жизненного цикла она находится? Очевидным будет ответ, что руководство должно иметь представление о стадии жизненного цикла, на которой находится организация, а значит, и возможность вовремя предотвратить возможные кризисы и выстроить стратегию. Но необходимо ли финансовой службе компании также иметь представление о стадии жизненного цикла, на котором находится она, ее продукты и ее бизнес-направления? Чем понимание фаз жизненного цикла компании может помочь в решении финансовых задач? И только ли для крупных российских компаний важен процесс построения их жизненного цикла, отрасли и их постоянный мониторинг?

В классических теориях и исследованиях по анализу и проектированию организаций, как правило, рассматриваются зрелые или находящиеся на определенном этапе развития компании, при этом не учитываются детально предшествующие этапы развития организации или дальнейшие перспективы ее развития.

Тем не менее на сегодняшний день уже сформировалось направление, которое подходит к организации не только как к системе, существующей в определенный период времени, но и как к объекту, который уже развивался до момента анализа и будет развиваться дальше. Эти исследования основываются на теории жизненных циклов, что в общем может быть принято для объяснения процесса развития организации, так как

\footnotetext{
${ }^{42}$ Выпускница программы МBA ВШМ ГУ-ВШЭ, слушатель программы DBA ВШМ ГУ-ВШЭ.
} 
практически у любой существующей на сегодняшний день на российском рынке, организации (крупной и небольшой, публичной и закрытой) были этапы создания, роста / развития, далее следуют этапы процветания и стабилизации; но возможны и спад, затухание и исчезновение. Тем не менее существуют и оправданные критические замечания при принятии теории жизненных циклов для исследования и описания организации биологическая теория жизненного цикла говорит о том, что рано или поздно у любого биологического объекта наступит смерть, чего нельзя сказать об организации, так как есть примеры, когда «умирающие» организации возрождались и /или принимали другие формы, начинали новую жизнь после изменений / реинкарнации. Кроме того, для организаций не существует, в отличие от биологического объекта, четкой линейной последовательности этапов жизненного цикла и нельзя точно определить время существования на том или ином этапе, хотя общее сходство этапов просматривается.

Несмотря на определенную критику теории жизненных циклов при использовании ее для исследования организаций, на сегодняшний день существует уже достаточно длинный ряд моделей, описывающих организации именно с точки зрения их жизненных циклов. Кроме того, исследования показали, что определение этапа развития организации при ее диагностике позволяет избежать ряда ошибок при определении как нынешнего состояния организации, так и планирования ее дальнейшего развития. П рактически все исследования проводились на развитых западных (в основном американских рынках) и по понятным причинам рассматривали публичные компании. Тем не менее общие тенденции можно применить и к российским компаниям, включая закрытые.

Приведем известную практически всем маркетологам кривую жизненного цикла по модели И. Адизеса [Adizes I., 1988].

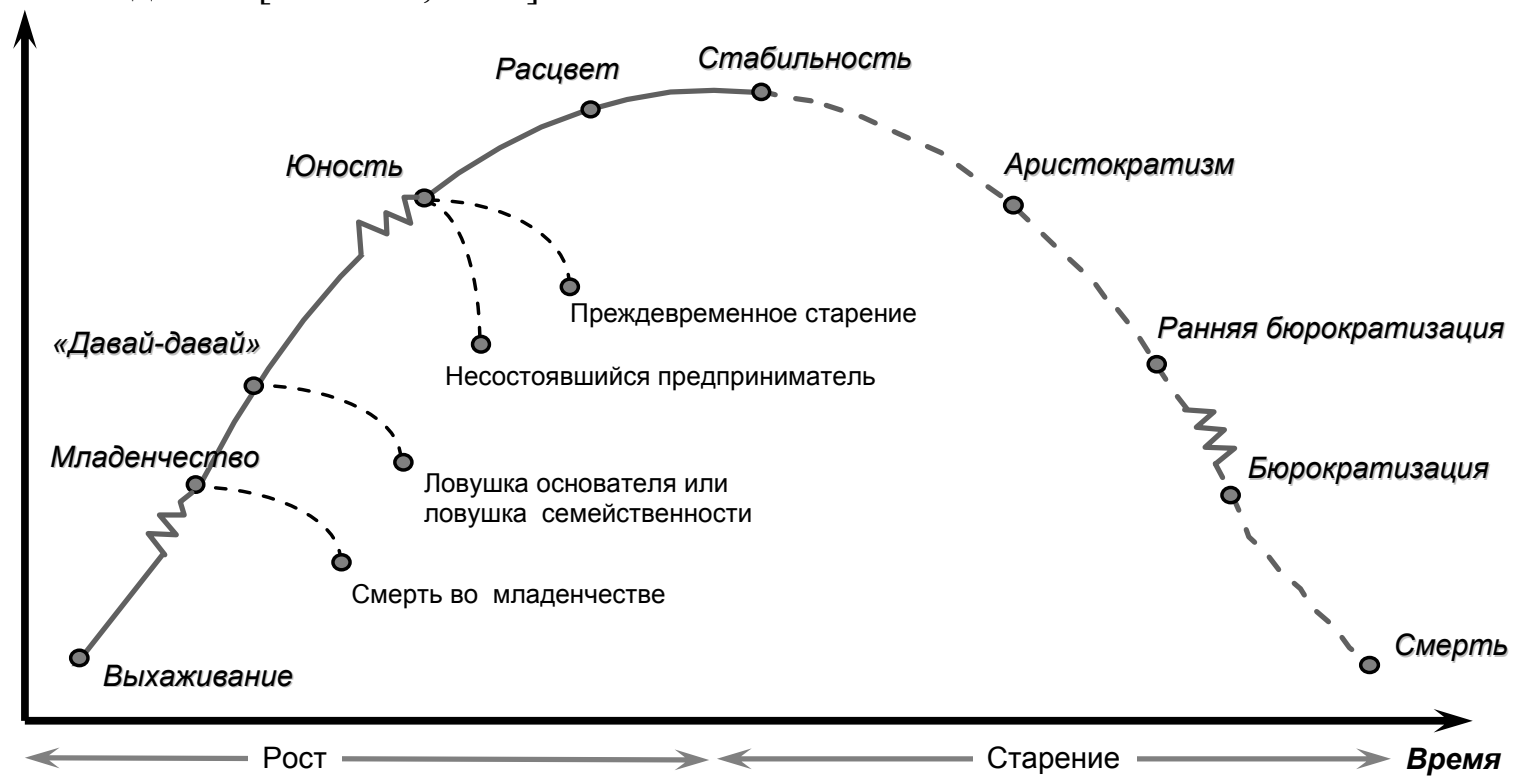

Рис. 1. Кривая жизненного изикла по модели И. Адизеса

Используя определенные критерии, характерные для той или иной стадии развития организации, с определенной достоверностью мы можем определить, на какой стадии развития находится организация. Но скорее всего, применяя только одну модель, мы поймем: по каким-то показателям мы находимся на одной стадии развития, а по другим - на совершенно другой.

Для того чтобы более точно определить, на каком этапе развития находится организация и какие проблемы у нее могут возникнуть (помимо указанных Адизесом), необходимо, на мой взгляд, проанализировать организацию по нескольким моделям, так как существующие на сегодняшний день модели, как правило, рассматривают организацию с различных точек зрения с учетом разных аспектов развития организации, а именно: с точки зрения теории развития личности (как модель у Липпита и Шмидта); с точки зрения 
эволюционных и революционных этапов развития организации, где переход на новый этап основывается на прошлом опыте (как модель Грейнера); с точки зрения менталитета членов организации (как у Торберта); с точки зрения личностной характеристики основателя организации (как у Кимберли); с точки зрения развития и изменения корпоративной культуры (как в модели Шайна); и, как уже говорилось, с точки зрения роста и старения (как в модели Адизеса).

Наверняка сложность при оценке компании (или бизнеса) будет состоять в том, что компания уже существует на рынке несколько лет и, возможно, уже сгенерировала несколько новых бизнес-единиц или бизнес-направлений, которые находятся на разных этапах жизненного цикла. Тем не менее, использовав несколько моделей одновременно и определив стадию жизненного цикла компании и ее отдельных направлений, бизнес-единиц, вы придете к более четкому пониманию стадии жизненного цикла как вашей организации в целом, так и ее отдельных направлений, что позволит вам выявить существующие проблемы сегодня и найти возможные пути их разрешения, а также определить возможные тенденции дальнейшего развития организации и заблаговременно принять меры, чтобы сгладить проблемы в будущем.

Для компаний, работающих на российском рынке услуг, можно использовать две-три модели - уже упомянутую модель Адизеса, модель Грейнера и модель Кимберли (особенно если у вас частный закрытый бизнес), либо еще одну из перечисленных выше моделей (в зависимости от того, какие характеристики более критичны для вашей организации или для вас лично, если вы ее собственник). Сложности при определении стадии жизненного цикла компании могут состоять в следующем: возможно, что от начала основания до сегодняшнего дня бизнес (или компания) уже пережил несколько реинкарнаций; или разделился на несколько компаний; или определялись разные стратегии для разных бизнес-единиц или направлений; у бизнес-единиц могло быть разное поведения на рынке и различные партнерские отношения; могли меняться принципы взаимоотношений с клиентами, корпоративная культура и т.д. Тем не менее важно попытаться разделить весь пройденный компанией путь на несколько этапов, периодов (как для компании в целом, так и для ее бизнес-направлений) и разложить их отдельно на кривой жизненного цикла организации. Скорее всего, вы сразу поймете, что все эти изменения в компании объективно происходили, а реинкарнации (или появления в новом виде / качестве) случились вместо «смерти во младенчестве», что в общем и целом как раз и доказывает возможность применения моделей жизненных циклов к исследованию вашей организации, в вашем сегменте рынка. Для лучшего понимания и оценки вашей деятельности за прошедший период неплохо было бы сравнить изменение кривой жизненного цикла вашей организации с аналогичной кривой вашего конкурента, сегмента рынка, отрасли в целом (конечно, если есть такая возможность): это дополнительно поможет вам, как минимум, определить, насколько качественным был ваш рост (росли ли вы вместе с рынком, находитесь выше или ниже рынка, конкурента и т.д.).

Модель Грейнера, приводимая ниже, поможет определить управленческие практики, характерные для того или иного этапа развития компании и сравнить их с теми фактическими управленческими практиками, которые существовали и существуют в вашей компании (или компаниях) на сегодняшний день. 


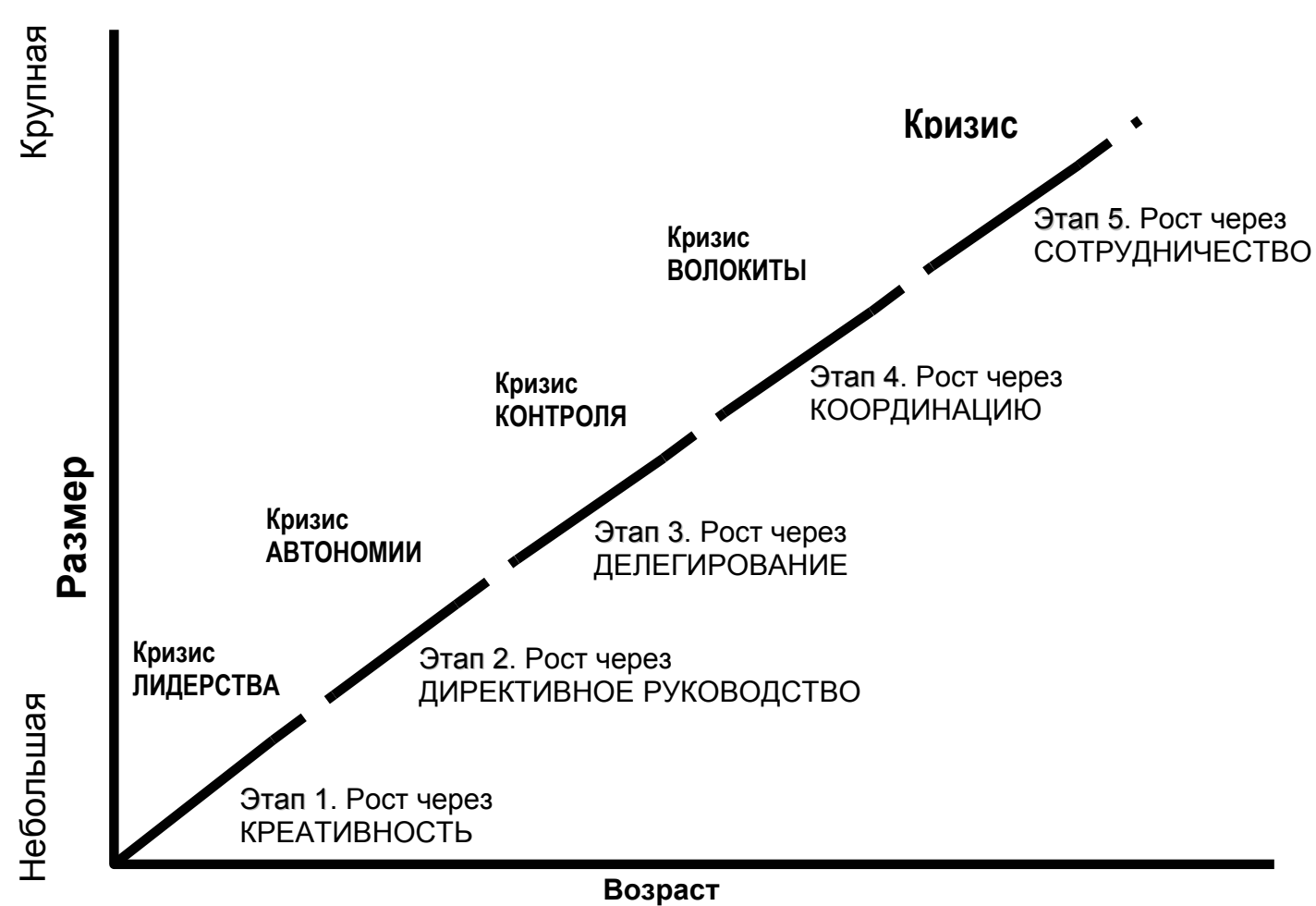

Рис. 2. Этапы роста организаиии по модели Л. Грейнера

Более внимательно посмотрев на этот график, можно заметить, что возраст компании по одной оси, как и размер компании по другой, не дают четких количественных характеристик - ни точного времени (в годах, месяцах), ни точного размера. Причем, не очень очевидно, что понимается под размером - количество сотрудников, размер генерируемого дохода или какие-то другие критерии. Кроме того, важно помнить, что размер компании (как по количеству работающего персонала, так и по генерируемому доходу) будет по-разному определяться для различных отраслей (консалтинговая компания с количеством сотрудников 500 человек вряд ли будет считаться маленькой или даже средней, тогда как для сырьевой отрасли такая компания явно небольшая).

Существует ряд критериев и аналитических исследований на российском рынке, по которым определяется, какие организации в какой отрасли к какому бизнесу относятся малому, среднему или крупному. В общем на сегодняшний день к среднему бизнесу принято относить компании с годовым оборотом от 8 до 25 млн евро - для таких секторов экономики, как оптовая и розничная торговля, производство, сфера услуг (кроме финансовых). Есть и другие критерии оценки, но в общем и целом совершенно очевидно, что огромный пласт российских компаний на сегодняшний день относится к среднему бизнесу; но это, как правило, закрытый бизнес, где обороты уже достаточно приличные (по российским меркам), а разработки новейших западных методик не нашли пока должного применения.

Нуждается ли закрытый средний бизнес в новейших западных концепциях и оценках? Думаю, вопрос будет решен в каждой отдельной компании индивидуально, поскольку нет требований о представлении такой информации. Но то, что эти концепции можно применять для российского закрытого бизнеса, - абсолютно очевидно.

Исходя из того, что уже было сказано выше (разные управленческие практики характерны для разных стадий развития; продукт/услуга генерирует различный доход на разных стадиях своего развития), совершенно логично предположить, что и основные финансовые показатели будут также различными на разных этапах жизненных циклов. Следовательно, финансовая аналитика, которую необходимо проводить в компании и на которую необходимо обращать внимание на разных этапах, должна быть различной - это позволит более корректно не только определять нынешнее финансовое состояние, но, главное, - строить прогнозы. 
Теперь попытаемся еще раз посмотреть на жизненный цикл организации, но уже с позиций финансовых измерений компании. Такой взгляд уже вынесен на обсуждение представлен в российской финансово-экономической литературе [Ивашковская И.В., Константинов Г.Н., Филонович С.Р., 2004; Ивашковская, 2006].В западной литературе уже появился ряд эмпирических исследований, проводившихся для западных компаний и доказавших, что финансовые характеристики компании изменяются при переходе от одного этапа жизненного цикла к другому. Ниже приведены характерные изменения денежных потоков в зависимости от прохождения компанией того или иного жизненного цикла [Ивашковская, 2006].

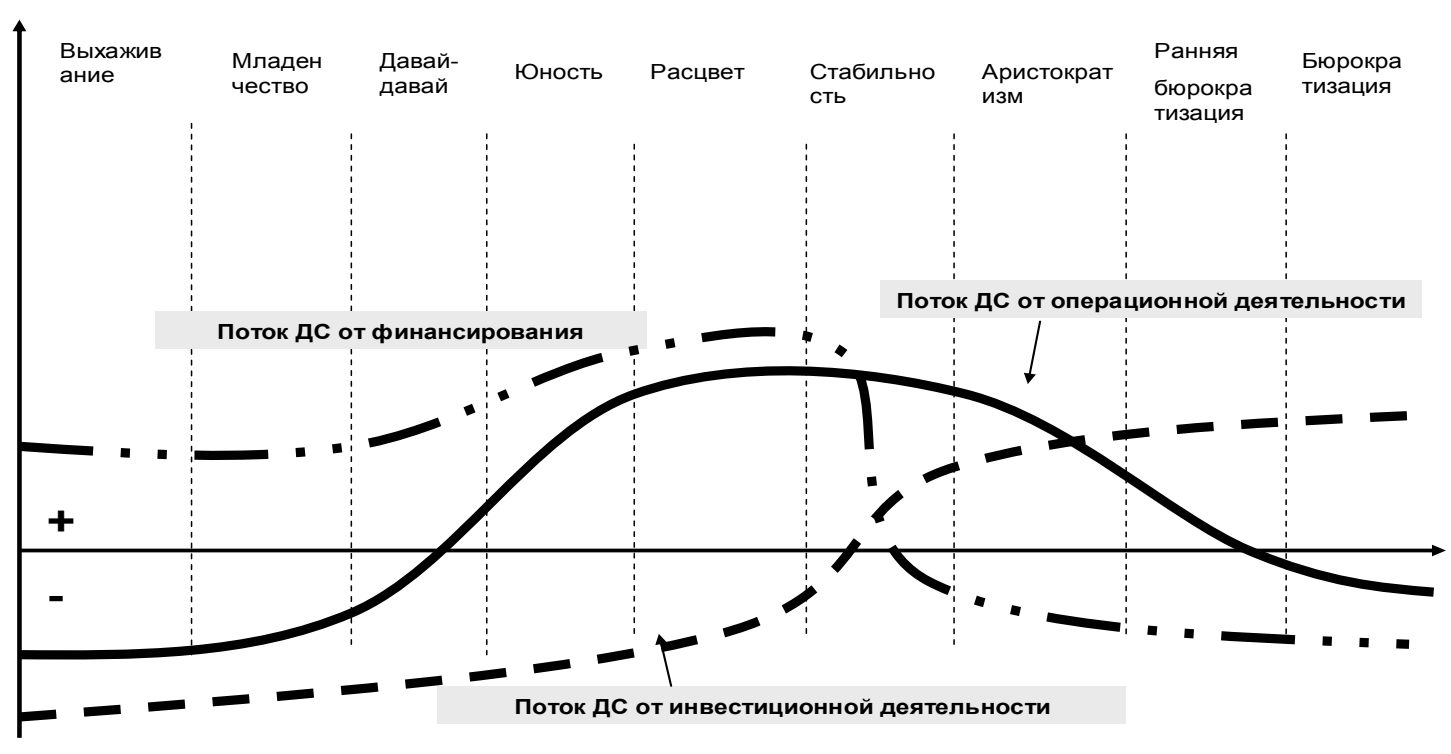

Рис. 3. Потоки денежных средств на стадиях ЖЦО

Не будем детально останавливаться на описании поведения кривых, они достаточно очевидно показывают проблемные места, что, собственно, и хотелось бы подчеркнуть: помимо управленческих и других возможных кризисов у компании могут возникать и финансовые кризисы - например, ликвидности бизнеса (что выражается в нехватке денежного оборотного капитала для текущей деятельности) и ликвидности капитала собственника (невозможность бизнеса генерировать положительный денежный поток, свободный для изъятия собственником).

Не буду утверждать, что для любого бизнеса точки перелома кривых (изменение знака потока) будут находиться именно в указанных на этом графике точках. Понятно, что бизнес сферы услуг и бизнес производства имеют не только различные потребности в оборотном капитале, но у них и сам операционный цикл другой. Важно иметь в виду, что такие кризисы объективны и возможны, важно предвидеть их появление и понимать, какие шаги можно предпринять для выхода из этих типов кризисов. Из графика на рисунка 3 также следует, что необходимо выводить операционный поток компании в зону положительных значений или подтянуть его от отрицательных значений до нулевой отметки и в то же время определить возможные пути финансирования бизнеса (как с помощью кредитных, заемных средств, так и по возможности за счет работы с «естественными» кредиторами; другими словами - необходимо управлять дебиторской и кредиторской задолженностью).

Сложность анализа ваших потоков денежных средств, особенно если у вас диверсифицированный бизнес (или группа компаний), будет состоять в том, что компании/ бизнес-единицы могут находиться на разных этапах жизненных циклов - как по отношению Выпуск \#4, 2007 
друг к другу, так и по отношению к группе (или материнской компании) в целом. Тем не менее, понимая общие тренды движения потоков, но, учитывая специфику вашего бизнеса, можно применить основные тенденции как к одной отдельной компании в группе, так и к группе в целом. Причем я четко убеждена в том, что, проведя такой анализ внутри ваших бизнес-направлений или отдельных компаний, вы можете обнаружить, что у вас происходит смещение не только жизненных циклов отдельных бизнес-единиц, но и потоков (как в количественном, так и в качественном выражении), именно поэтому важно все же провести анализ по каждому бизнес-направлению отдельно. В общем, при умелом управлении вашими консолидированными потоками с учетом разных характеров потоков по отдельным направлениям бизнес-активности вы сможете использовать так называемое, «внутреннее кредитование» внутри вашего бизнеса в целом. Это не панацея от всех бед, но, тем не менее, на краткосрочный период и при невозможности получения финансирования из других источников такие кредиты можно использовать. Один из моментов, которые необходимо учитывать при выдаче «внутренних кредитов», - это проблема корректного отражения процентов по «кредиту» и интереса между компаниями (плюс дополнительный интерес к доходам для тех, кто выдал внутренний кредит, а минус - расход для тех, кто использовал внутренние кредиты). Если не договориться о таких правилах игры (о ставке, периоде кредитования и т.д.) и не отразить эти дополнительные доходы и расходы в каждом отдельном бизнес-направлении, то получится искаженное понимание результатов того или иного подразделения, так как будут завышены показатели компании-заемщика. С другой стороны, с точки зрения собственников, при рассмотрении не отдельных операционных бизнесов компаний, а консолидированных показателей по группе это не будет иметь существенного значения, так как такие проценты по внутренним кредитам все равно будут нивелироваться внутри группы. Тем не менее, если у вас налажен раздельный учет (по отдельным структурным единицам, по различным бизнес-направлениям), важно делать такие начисления, корректировки к результатам, чтобы сравнивать показатели отдельных направлений с учетом даже кажущихся невидимыми факторов, поскольку анализ, который каждая компания пытается провести, все же в конечном счете необходим для принятия корректных стратегических решений, для того, чтобы понимать, какие направления являются более интересными, прибыльными для собственника, какие необходимо развивать или в какие инвестировать, а какие реструктурировать или закрывать.

Хочется остановиться на понятии «инвестирование». Традиционный подход определяет достаточно точно инвестиции в основные фонды и даже в нематериальные активы. Но если ваш бизнес не фондоемкий, не производственный, а вы занимаетесь профессиональными услугами, то важно определить, будут ли считаться инвестициями расходы (в явном или не всегда явном/рассчитанном эквиваленте), связанные с повышением уровня «производительности» вашего основного для этого бизнеса капитала - человеческого. Отрицать, что это капитал, я думаю, вряд ли кто-то будет, так как именно этот капитал позволяет компании генерировать денежный поток, а совсем не офисное оборудование или программный продукт, на котором производится основной интеллектуальный продукт компании - ее качественная профессиональная услуга. Понятно, что сложно точно определить, как сами инвестиции в этот капитал, так и периоды окупаемости таких инвестиционных проектов, но тем не менее не в традиционном - бухгалтерском — подходе, а в ряде современных финансовых концепций и разработок такие попытки делаются.

Очевидно, что можно и нужно анализировать по кривой жизненного цикла не только публичные компании, но и закрытые, чтобы принимать верные стратегические решения. Будет ли у вас на первом этапе только анализ прибыли и денежных потоков, или же вы уже готовы к анализу с позиций современной финансовой аналитики, который рассматривает развитие конкретной компании на протяжении ЖЦО в системе ключевых финансовых координат: ликвидности, инвестиционного риска и подлинной стоимости компании, - но очевидным на сегодняшний день является тот факт, что успешная компания добивается правильного соотношения указанных трех финансовых измерений. Результатом такого 
успеха будет получение потока денежных средств, достаточного не просто для покрытия расходов, включая инвестиционные, но и - главное - для компенсации инвестиционных рисков. В финансовых координатах кривая жизненного цикла компании - это линия ее жизни в мире экономической, а не бухгалтерской прибыли. Проходя этапы жизненного цикла, компания должна быть нацелена на достижение положительной экономической прибыли, на создание перспективы ее приращения в будущем, на рост не просто в терминах выручки (оборотов), активов, бухгалтерской прибыли, а на рост капитала в терминах увеличения инвестиционной стоимости ее бизнеса. Поэтому при формировании системы корпоративного управления необходимо обеспечить ее настройку на выбор правильных показателей, адекватно отражающих объективно существующие финансовые измерения компании. Эта непростая задача, но ее надо начинать решать, если планируется длительная и успешная жизнь на сильно конкурирующих рынках.

\section{Список литературы}

1. Кулешевич Е.И., Филонович С.Р. Модели жизненных циклов организаций. В кн.: Виханский О. С., Наумов А. И. (ред.). Менеджмент: век XX - век XXI. М.: Экономистъ, c.304-320.

2. Ивашковская И.В., Константинов Г.Н., Филонович С.Р. Становление корпорации в контексте жизненного цикла организации / Российский журнал менеджмента, 2004, № 4, c. $19-34$.

3. Ивашковская И.В. Жизненный цикл организации: взгляд финансиста / Управление компанией, 2006, № 11.

4. Грейнер Л. Эволюция и революция в процессе роста организаций / Вестник С.-Петербургского ун-та. Сер. Менеджмент (4): 2002, с. 76-92.

5. Adizes I. Corporate Lifecycles: How and Why Corporations Grow and Die and What to Do about It. Englewood Cliffs, N.J.: Prentice Hall, 1988. 